\title{
Evidence-based clinical practice update: practice guidelines for anterior cruciate ligament rehabilitation based on a systematic review and multidisciplinary consensus
}

\author{
Nicky van Melick, ${ }^{1,2}$ Robert E H van Cingel, ${ }^{3,4}$ Frans Brooijmans, ${ }^{5}$ Camille Neeter, ${ }^{6}$ \\ Tony van Tienen, ${ }^{7}$ Wim Hullegie, ${ }^{8}$ Maria W G Nijhuis-van der Sanden ${ }^{1}$
}

\begin{abstract}
- Additional material is
published online only. To view please visit the journal online (http://dx.doi.org/10.1136/ bjsports-2015-095898).

${ }^{1}$ Funqtio, Steyl, The

Netherlands

${ }^{2}$ Radboud University Medical Center, Research Institute for Health Sciences, IQ healthcare, Nijmegen, The Netherlands

${ }^{3}$ Sport Medisch Centrum Papendal, Arnhem, The Netherlands

${ }^{4}$ Research Group

Musculoskeletal Rehabilitation, HAN University of Applied

Sciences, Nijmegen, The Netherlands

${ }^{5}$ B\&sis, Eindhoven, The Netherlands

${ }^{6}$ Neeter Fysiotherapie,

Amsterdam, The Netherlands

${ }^{7}$ Kliniek ViaSana, Mill,

The Netherlands

${ }^{8}$ FysioGym Topsport, Enschede,

The Netherlands
\end{abstract}

\section{Correspondence to}

Nicky van Melick, Funqtio,

Triangelstraat $1 \mathrm{~F}$,

Steyl 5935 AG,

The Netherlands;

nicky@funqtio.nl

Accepted 28 July 2016 Published Online First 18 August 2016

\section{ABSTRACT}

Aim The Royal Dutch Society for Physical Therapy (KNGF) instructed a multidisciplinary group of Dutch anterior cruciate ligament $(A C L)$ experts to develop an evidence statement for rehabilitation after $\mathrm{ACL}$ reconstruction.

Design Clinical practice guideline underpinned by systematic review and expert consensus.

Data sources A multidisciplinary working group and steering group systematically reviewed the literature and wrote the guideline. MEDLINE and the Cochrane Library were searched for meta-analyses, systematic reviews, randomised controlled trials and prospective cohort studies published between January 1990 and June 2015.

Eligibility criteria for selecting studies Included literature must have addressed 1 of 9 predetermined clinical topics: (1) preoperative predictors for postoperative outcome, (2) effectiveness of physical therapy, (3) open and closed kinetic chain quadriceps exercises, (4) strength and neuromuscular training, (5) electrostimulation and electromyographic feedback, (6) cryotherapy, (7) measurements of functional performance, (8) return to play and (9) risk for reinjury. Summary Ninety studies were included as the basis for the evidence statement. Rehabilitation after $A C L$ injury should include a prehabilitation phase and 3 criterionbased postoperative phases: (1) impairment-based, (2) sport-specific training and (3) return to play. A battery of strength and hop tests, quality of movement and psychological tests should be used to guide progression from one rehabilitation stage to the next. Postoperative rehabilitation should continue for 9-12 months. To assess readiness to return to play and the risk for reinjury, a test battery, including strength tests, hop tests and measurement of movement quality, should be used.

\section{INTRODUCTION}

Anterior cruciate ligament reconstruction (ACLR) is a common treatment for athletes after ACL injury. The incidence of non-contact ACL injuries appears to be the greatest in athletes who are between 15 and 40 years of age and participate in pivoting sports like soccer, handball, volleyball and alpine skiing. ${ }^{12}$ Every year, about $3 \%$ of amateur athletes injure their ACL; for elite athletes, this percentage could be as high as $15 \% .^{2}$ Females are two to eight times more likely to sustain an ACL injury than their male counterparts, probably because male and female neuromuscular patterns diverge during and following puberty. ${ }^{3-8}$

Besides its mechanical function in maintaining knee stability, the ACL contains mechanoreceptors $(2.5 \%)$ and therefore directly influences the neuromuscular control of the knee. ${ }^{9}$ ACL deficiency causes partial deafferentiation and alters spinal and supraspinal motor control. The changes in motor control strategy can reveal changes in proprioception, postural control, muscle strength, movement and recruitment patterns. ${ }^{10}$ An ACL injury might therefore be regarded as a neurophysiological dysfunction and not a simple peripheral musculoskeletal injury. ${ }^{11}{ }^{12}$ It is also not self-evident that an ACLR will automatically lead to a return to preinjury activity level.

Recent research shows that $35 \%$ of athletes after ACLR do not return to preinjury sport level within 2 years. ${ }^{13-15}$ Half of these athletes report their ACL injury as the primary reason for a lower activity level. ${ }^{13} 14 \quad 16-18$ Apart from the physical recovery, also the psychological response (eg, fear of reinjury) after ACLR has an influence on whether an athlete chooses to return to play. ${ }^{19-25}$ Return to play is defined as the ability to play a competitive match at the preinjury level. Moreover, recent research shows that $3-22 \%$ of athletes rerupture the reconstructed ligament and 3-24\% rupture the contralateral ACL in the first 5 years after ACLR. ${ }^{17}$ 26-30

The difficulty with determining the moment of return to play is that it is unknown which measures should be used to predict a safe return to play with a low risk of a second ACL injury. Three recent systematic reviews show that the return-to-play decision by clinicians is hardly based on objective clinimetric criteria. $^{27} 3132$ Furthermore, these studies concluded that return to play is only connected to quantitative criteria, while it is known that qualitative criteria (eg, dynamic knee valgus, knee flexion angle and trunk control) play an important role in prevention and rehabilitation. Movement quality actually may affect the ACL (re) injury rate. ${ }^{33}$ The occurrence of dynamic knee valgus when landing from a jump, for instance, increases the risk of ACL (re)injury. ${ }^{35} 36$

Return to play is the ultimate goal of rehabilitation programmes. So the above-mentioned factors are important topics to incorporate in the rehabilitation process after ACLR. However, currently, there is no consensus regarding the content of a 
rehabilitation programme. Therefore, the Royal Dutch Society for Physical Therapy (KNGF) instructed a multidisciplinary group of ACL experts in the Netherlands to develop an evidence statement for anterior cruciate ligament rehabilitation. The goal of this evidence statement was to describe the rehabilitation after ACLR and to encourage uniformity in physical therapy treatment and use of measurements of functional performance. The following three questions were formulated by a steering group of the KNGF to guide the realisation of the evidence statement:

1. What should be the content of the rehabilitation protocol after ACLR based on scientific evidence and, if not present, based on best practice?

2. Which measurements and assessments can be applied to monitor progression during the rehabilitation programme and to determine outcomes at the end of rehabilitation programme?

3. What criteria should be used to determine the moment of return to play?

\section{METHODS}

\section{Expert participants}

The process started with the formation of a multidisciplinary working group and steering group. The working group consisted of six Dutch ACL experts with 8-35 years of experience in ACL rehabilitation: five physical therapists specialised in sports injury rehabilitation and one orthopaedic surgeon specialised in knee surgery, ACL surgery in particular. The steering group consisted of ACL experts from different professions with 10-37 years of experience in ACL rehabilitation (three physical therapists, one sports physician, one orthopaedic surgeon and one trauma surgeon).

\section{Procedure}

The first author (NvM) chaired the working group and was responsible for the systematic review steps (literature search, methodological quality assessment, data extraction, data analysis, description of the results and translation into practice guidelines) and for writing the evidence statement. The working group monitored each step in the systematic review process and assisted in methodological quality assessment of the included studies, the writing process and the translation into practice guidelines. The steering group (chairman $\mathrm{REHvC}$ ) validated all steps made by the first author and the working group. The KNGF assisted in the administrative processes.

The working group contacted each other by email and every 2 months a consensus meeting was organised. Every other meeting, the steering group joined the working group.

The first meeting of the working and steering group together, started with the formulation of nine clinical topics important for ACLR rehabilitation. These topics were used to guide the systematic review process. These nine topics were: (1) preoperative predictors for postoperative outcome, (2) effectiveness of physical therapy, (3) open kinetic chain (OKC) versus closed kinetic chain (CKC) quadriceps exercises, (4) strength training and neuromuscular training, (5) electrostimulation and electromyographic feedback, (6) cryotherapy, (7) measurements of functional performance, (8) return to play and (9) risk of reinjuries.

Articles found during the systematic review process were subdivided into the nine topics and every topic was given a level of evidence according to the EBRO (Dutch evidence-based guideline development) criteria. ${ }^{37}$ The recommendations were, if available, based on the latest scientific evidence, supplemented with best practice when necessary. The results of the systematic review process (see online supplementary appendix 1) were used to formulate the evidence statement (see online supplementary appendix 2 ).

\section{Search strategy}

A systematic literature search was performed searching in MEDLINE (PubMed) and the Cochrane Library to identify relevant articles from January 1990 up to June 2015 using keywords specified for the database according to the nine topics mentioned above with PICO questions (table 1). An academic librarian composed a syntax based on all the keywords. Meta-analyses, systematic reviews, randomised controlled trials (RCTs) and prospective cohort studies were included for study selection.

\section{Study selection}

All eligible articles were screened first by title and abstract independently by two reviewers (NvM and $\mathrm{REHvC}$ ). When the two reviewers did not reach consensus, a third reviewer $(\mathrm{CN})$ made the final decision. After this first inclusion, the full-text article was screened using the inclusion and exclusion criteria as listed in table 2. In addition, a hand search was performed on the reference lists of meta-analysis and systematic reviews for RCTs and prospective cohort studies that were not included in the primary search. A flow chart of the search strategy is presented in figure 1.

\section{Methodological quality assessment}

Quality assessment of the included articles was independently performed by two reviewers ( $\mathrm{NvM}$ and $\mathrm{REHvC})$. When the reviewers did not reach consensus, a third reviewer made the final decision. All articles were individually graded for level of methodological quality (table 3 and online supplementary appendix 1).

Methodological quality of meta-analyses and systematic reviews was assessed with the AMSTAR checklist. The assessment of risk of bias of the RCTs was performed with the PEDro scale (http://www.pedro.org.au). The PEDro scale was scored on 10 items. Methodological quality was rated poor when an article had a score of $\leq 4$. Subsequently, the RCTs with poor quality were excluded.

The prospective cohort studies were assessed with an adapted Cochrane Library Checklist (table 4), also used before in the KNGF guideline for urinary incontinence. ${ }^{38}$ This checklist has a maximum score of 5 . Prospective cohort studies were only used when no higher level evidence was available or to support findings in the RCTs.

\section{Data extraction}

Data extraction was performed by one reviewer (NvM). See online supplementary appendix 1 for the data extraction table. Results from the included studies were synthesised descriptively for the evidence statement. Based on the results of all articles selected in one topic, a final conclusion was made with a corresponding level of evidence (table 5). ${ }^{37}{ }^{39}$ To correct for double evidence, RCTs that were also included in a meta-analysis or systematic review were not used separately to determine the level of evidence of the final conclusion.

\section{RESULTS}

Study selection and methodological quality assessment

After removing doubles, the systematic literature search in MEDLINE and the Cochrane Library provided 3713 articles 
Table 1 Search strategy 31 May 2015

\begin{tabular}{|c|c|c|}
\hline & $\begin{array}{l}\text { Citations } \\
\text { MEDLINE }\end{array}$ & $\begin{array}{l}\text { Citations } \\
\text { Cochrane }\end{array}$ \\
\hline 1: anterior cruciate ligament [Mesh] & 10170 & 739 \\
\hline 2: anterior cruciate ligament [tiab] & 11970 & 1359 \\
\hline 3: anterior cruciate ligaments [tiab] & 331 & - \\
\hline 4: ACL [tiab] & 10402 & 853 \\
\hline 5: $1-4$ with OR & 17340 & 1596 \\
\hline 6: anterior cruciate ligament reconstruction [Mesh] & 1794 & 179 \\
\hline 7: anterior cruciate ligament reconstruction [tiab] & 3903 & 968 \\
\hline 8: anterior cruciate ligament/surgery [Mesh] & 6451 & - \\
\hline 9: reconstructive surgical procedures [Mesh] & 143978 & 6051 \\
\hline 10: reconstructive surgical procedures [tiab] & 149 & 908 \\
\hline 11: reconstructive surgical procedure [tiab] & 32 & - \\
\hline 12: reconstruction [tiab] & 142371 & 3348 \\
\hline 13: reconstructed [tiab] & 39500 & 474 \\
\hline 14: reconstructive [tiab] & 25421 & 1187 \\
\hline 15: ligament surgery [tiab] & 317 & 930 \\
\hline 16: bone-patellar tendon-bone grafts [Mesh] & 14 & - \\
\hline 17: bone-patellar tendon-bone grafts [tiab] & 67 & - \\
\hline 18: bone-patellar tendon-bone graft [tiab] & 212 & 94 \\
\hline 19: tendon graft [tiab] & 1357 & 247 \\
\hline 20: tendon grafts [tiab] & 699 & - \\
\hline 21: tendon transfer [Mesh] & 3540 & 62 \\
\hline 22: tendon transfer [tiab] & 1302 & 83 \\
\hline 23: tendon transfers [tiab] & 674 & - \\
\hline 24: orthopedic procedures [Mesh] & 213556 & 9925 \\
\hline 25: orthopedic procedures [tiab] & 680 & 1350 \\
\hline 26: orthopedic procedure [tiab] & 124 & - \\
\hline 27: orthopaedic procedures [tiab] & 523 & - \\
\hline 28: orthopaedic procedure [tiab] & 107 & - \\
\hline 29: 6-28 with OR & 444486 & 15852 \\
\hline 30: physical therapy modalities [Mesh] & 129118 & 16446 \\
\hline 31: physical therapy [tiab] & 11921 & 18473 \\
\hline 32: physiotherapy [tiab] & 12631 & 3939 \\
\hline 33: kinesiotherapy [tiab] & 114 & 850 \\
\hline 34: exercise therapy [tiab] & 2120 & 16047 \\
\hline 35: postoperative care [Mesh] & 52666 & 3903 \\
\hline 36: postoperative care [tiab] & 4852 & 13295 \\
\hline 37: rehabilitation [Mesh] & 154448 & 15806 \\
\hline 38: rehabilitation [tiab] & 110195 & 14259 \\
\hline 39: rehabilitation [subheading] & 168951 & 13952 \\
\hline 40: instruction [tiab] & 20681 & 3773 \\
\hline 41: instructions [tiab] & 21227 & - \\
\hline 42: resistance training [Mesh] & 3752 & 1255 \\
\hline 43: resistance training [tiab] & 4168 & 4113 \\
\hline 44: strength training [tiab] & 3137 & 4966 \\
\hline 45: neuromuscular training [tiab] & 227 & 631 \\
\hline 46: exercise [Mesh] & 124975 & 14346 \\
\hline 47: exercise [tiab] & 188673 & 42289 \\
\hline 48: exercises [tiab] & 25022 & - \\
\hline 49: testing [tiab] & 376479 & 23811 \\
\hline 50: test [tiab] & 1057291 & 101340 \\
\hline 51: tests [tiab] & 484232 & - \\
\hline 52: $30-51$ with OR & 2266540 & 190016 \\
\hline 53: 5 and 29 and 54 & 4252 & 580 \\
\hline $\begin{array}{l}\text { 54: inclusion publication date } 1990-01-01 \text { until } \\
\text { 2015-05-31 }\end{array}$ & 4051 & 544 \\
\hline 55: inclusion language English & 3619 & 529 \\
\hline
\end{tabular}

Table 2 Inclusion and exclusion criteria for literature search

\begin{tabular}{|c|c|}
\hline Inclusion & Exclusion \\
\hline $\begin{array}{l}\text { Date of publication: January 1990- } \\
\text { June } 2015 \\
\text { English language } \\
\text { Meta-analyses, systematic reviews, } \\
\text { RCTs and prospective cohort studies } \\
\text { Full text available } \\
\text { Articles about brace-free rehabilitation } \\
\text { after arthroscopic ACLR with BPTB or } \\
\text { HS autograft } \\
\text { Articles including information on one } \\
\text { of the } 9 \text { clinical topics formulated by } \\
\text { the experts }\end{array}$ & $\begin{array}{l}\text { Narrative reviews, retrospective } \\
\text { cohort studies, case studies } \\
\text { Articles about non-operative } \\
\text { treatment } \\
\text { Articles about allograft, synthetic } \\
\text { graft or other autograft than BPTB } \\
\text { or HS } \\
\text { Articles about ACL revision } \\
\text { reconstruction } \\
\text { Articles with follow-up } \\
\text { measurement, but no description } \\
\text { of the rehabilitation protocol } \\
\text { Articles about operative } \\
\text { techniques, timing of the } \\
\text { operation or graft choice } \\
\text { Articles about bracing after ACLR } \\
\text { Articles about skeletally immature } \\
\text { patients } \\
\text { Animal, cadaveric or in vivo } \\
\text { studies }\end{array}$ \\
\hline
\end{tabular}

$\mathrm{ACLR}$, anterior cruciate ligament reconstruction; BPTB, bone-patellar tendon-bone; $\mathrm{HS}$, hamstring; RCT, randomised controlled trial.

(figure 1). After the first exclusion based on title and abstract, 101 articles were included for full-text assessment. After reading, no study was excluded. After the hand search in the reference lists of meta-analyses and systematic reviews, eight articles were included additionally. After quality assessment, 19 RCTs were excluded based on a PEDro score of $\leq 4$. The most common flaws were no blinding of participants, therapists or outcome assessors and an inadequate percentage of participants eligible for follow-up.

All final included $(n=90)$ articles were arranged by topic: 10 for preoperative predictors for postoperative outcome, ${ }^{40-49} 10$ for effectiveness of physical therapy, ${ }^{50-59} 11$ for OKC versus CKC quadriceps exercises, ${ }^{60-70} 21$ for strength training and neuromuscular training, ${ }^{71-91} 11$ for electrostimulation and electromyographic feedback, ${ }^{63}{ }^{93-102} 5$ for cryotherapy, ${ }^{103-107} 8$ for measurements of functional performance, ${ }^{27} \quad 31 \quad 32 \quad 108-112 \quad 10$ for return to play $^{13} 14^{17} \quad 22^{113-118}$ and 5 for risk of reinjuries $^{29} 3536119120$ (topics 'open vs closed kinetic chain quadriceps exercises' and 'electrostimulation' share one systematic review).

\section{Data extraction}

Evidence for clinical practice at all nine topics is summarised below, according to table 5. See also online supplementary appendix 1 for the data extraction table. Final recommendations were made according to the EBRO criteria in table 5.

Preoperative predictors for postoperative outcome

Ten articles were found about preoperative predictors for postoperative outcome. These were one systematic review, ${ }^{40}$ one $\mathrm{RCT}^{41}$ and eight prospective cohort studies. ${ }^{42-49}$

The prospective cohort studies of Eitzen et al, ${ }^{42}$ Heijne et $a l,{ }^{44} \mathrm{McHugh}$ et $a l^{47}$ and McHugh et $a l^{48}$ were included in the systematic review of de Valk et al. ${ }^{40}$ This level A2 systematic review documented that (1) better functional outcomes after ACLR were achieved for men than for women at a minimum follow-up of 1 year after ACLR, no matter the graft choice; (2) 


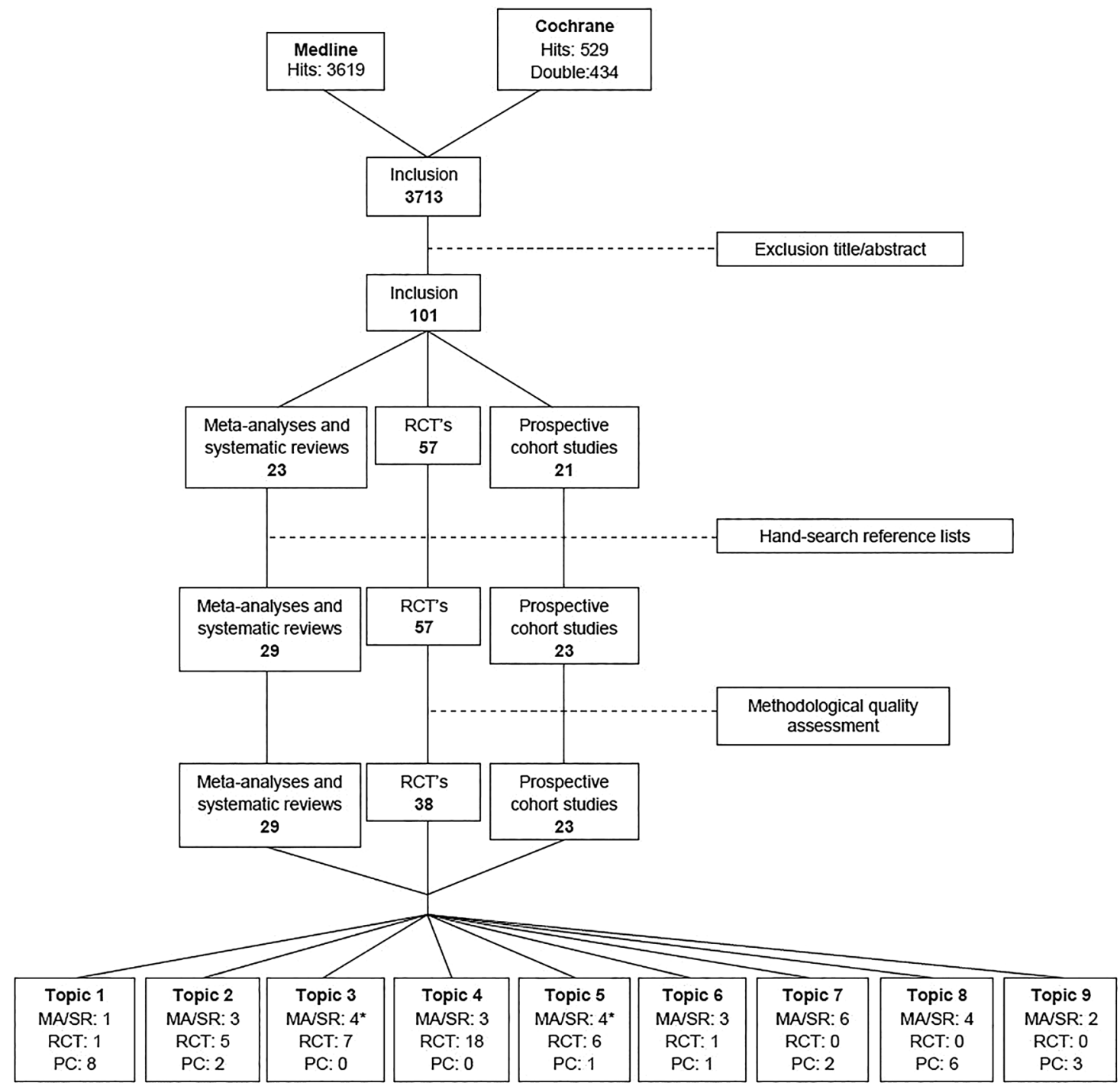

Figure 1 Flow chart of search strategy on 31 May 2015. *Topics 3 and 5 share one SR. MA, meta-analysis; PC, prospective cohort study; RCT, randomised controlled trial; SR, systematic review.

Table 3 Grading of the level of methodological quality of individual studies (EBRO)

\begin{tabular}{|c|c|c|c|}
\hline $\begin{array}{l}\text { Level of } \\
\text { evidence }\end{array}$ & Interventional studies & Diagnostic accuracy studies & Harm, side effects, aetiology, prognosis \\
\hline A1 & \multicolumn{3}{|c|}{ Systematic review/meta-analysis of at least two independently conducted studies of A2 level } \\
\hline $\mathrm{A} 2$ & $\begin{array}{l}\text { Randomised, double blind trial with good } \\
\text { study quality and an adequate number of } \\
\text { study participants }\end{array}$ & $\begin{array}{l}\text { Index test compared to reference test (reference standard); } \\
\text { cut-offs were defined a priori; independent interpretation of } \\
\text { test results; an adequate number of consecutive patients } \\
\text { were enrolled; all patients received both tests }\end{array}$ & $\begin{array}{l}\text { Prospective cohort study of sufficient magnitude } \\
\text { and follow-up, adequately controlled for } \\
\text { 'confounding' and no selective follow-up }\end{array}$ \\
\hline B & $\begin{array}{l}\text { Clinical trial, but without all the features } \\
\text { mentioned for level A2 (including case- } \\
\text { control study, cohort study) }\end{array}$ & $\begin{array}{l}\text { Index test compared to reference test, but without all the } \\
\text { features mentioned for level A2 }\end{array}$ & $\begin{array}{l}\text { Prospective cohort study, but without all the } \\
\text { features mentioned for level A2 or retrospective } \\
\text { cohort study or case-control study }\end{array}$ \\
\hline $\mathrm{C}$ & Non-comparative studies & & \\
\hline D & Expert opinion & & \\
\hline
\end{tabular}

patients younger than 30 years of age had a higher postoperative Tegner activity level than older patients at a minimal follow-up of 22 months after ACLR; (3) patients with ACLR within 3 months after injury and patients with a high preoperative Tegner activity level have a higher Tegner activity level at a minimal follow-up of 2 years after ACLR; (4) smoking, high
BMI (>30), quadriceps strength deficits and range of motion (ROM) deficits resulted in worse functional outcomes at a minimum of 1 year after ACLR. ${ }^{40}$ The steering group found some prospective cohort studies that supported the conclusions of de Valk et al. Lepley and Palmieri-Smith ${ }^{45}$ (level B) showed that preoperative quadriceps strength is positively related to 
Table 4 Adapted Cochrane library checklist

$$
\text { Item }
$$

1. Are inclusion and exclusion criteria reproducible?

2. Are the applied measurements reproducible?

3. Follow-up of participants is at least $80 \%$ ?

4. Is the analysis corrected for confounders?

5. Is outcome measure description reproducible?

Level of methodological quality

A2: all five items are scored positive

B: four of five items are scored positive

C: three or less items are scored positive

\section{Table 5 Level of evidence of the conclusion (EBRO)}

\begin{tabular}{ll}
\hline Level & Conclusion based on \\
\hline 1 & A1 study or at least two independent studies of level A2 \\
2 & One study of level A2 or at least two independent studies of level B \\
3 & One study of level B or C \\
4 & Expert opinion \\
\hline
\end{tabular}

postoperative quadriceps strength at the moment of return to play. Månsson et $a l^{46}$ (level C) found that a higher preoperative Tegner activity level predicts a better outcome at a minimal follow-up of 22 months. Quelard et al ${ }^{49}$ (level B) described that a limited preoperative ROM and female sex account for a limited ROM 3 months postoperative.

Grindem et $a l^{43}$ (level C prospective cohort study) and Shaarani et $a l^{41}$ (level B RCT) investigated the effect of preoperative rehabilitation, so-called prehabilitation, on the outcome after ACLR. Grindem et $a l^{43}$ described that combined prehabilitation and postoperative rehabilitation had better selfreported knee function at 2-year follow-up compared to postoperative rehabilitation only. Shaarani et $a l^{41}$ had a follow-up of only 12 weeks after ACLR. They found no differences in quadriceps and hamstring (HS) strength between a prehabilitation group and a group with no prehabilitation, but the prehabiliation group scored better on self-reported knee function. ${ }^{41}$

From the above-mentioned predictive factors, the nonmodifiable factors could be taken into account by the physical therapist to predict the outcome of treatment.

The conclusions about modifiable factors in this topic were as follows:

- Level 2: a preoperative extension deficit (lack of full extension) is a major risk factor for an extension deficit after ACLR. ${ }^{4049}$

- Level 2: a preoperative deficit in quadriceps strength of $>20 \%$ has a significant negative consequence for the selfreported outcome 2 years after ACLR. ${ }^{40} 45$

- Level 3: prehabilitation ensures better self-reported knee function up to 2 years after ACLR. ${ }^{41} 43$

\section{Effectiveness of physical therapy}

Ten articles were found about the effectiveness of postoperative physical therapy. These were three systematic reviews, ${ }^{50-52}$ five RCTs $^{53-57}$ and two prospective cohort studies. ${ }^{58} 59$

The systematic review of van Grinsven et $a l^{51}$ (level B) described a time-based rehabilitation protocol based on the available evidence supplemented with expert opinion.

The level A1 systematic review of Coppola and Collins ${ }^{50}$ investigated the effect of physical therapy after knee surgery. Based on
10 RCTs, they concluded that physical therapy is not more effective than a home exercise programme in a young and healthy population following relatively simple knee surgery as arthroscopic meniscectomy. However, for rehabilitation after complicated knee surgery as ACLR, there is a lack of evidence. ${ }^{50}$ The systematic review of Wright $e t a l^{52}$ (level A1) concluded that it is reasonable that a minimally supervised rehabilitation can result in successful ACLR rehabilitation. In their study, Coppola and Collins $^{50}$ included three RCTs about rehabilitation after ACLR. Wright et $a l^{52}$ included the same three RCTs plus the RCT of Beard and Dodd. ${ }^{53}$ The level B RCT of Beard and Dodd ${ }^{53}$ showed that physical therapy had minimal extra benefit in a, not explicitly described, young athletic population after ACLR. Their rehabilitation programme was only administered from weeks 4 to 16 after ACLR. They found no differences in self-reported knee function and quadriceps and HS strength 24 weeks after ACLR. ${ }^{53}$ Hohmann et $a l^{57}$ and Grant and Mohtadi ${ }^{56}$ (both level B) also investigated the difference between supervised physical therapy (Hohmann: 19 sessions, Grant and Mohtadi: 17 sessions) versus home-based rehabilitation (4 sessions). They both found no between-group differences in ROM, quadriceps and HS strength and hop tests at $>1$ year follow-up, ${ }^{56}$ but Grant and Mohtadi ${ }^{56}$ found a better self-reported knee function in the home-based group. The level C prospective cohort study of Dragicevic-Cvjetkovic et $a l^{58}$ found a better self-reported knee function and greater improvement in thigh muscle circumference in a rehabilitation group ( 20 weeks) compared to a group with no rehabilitation at all at a 1 year follow-up.

Both studies of Beynnon et $a l^{5455}$ (levels B and A2) studied the difference between a 19 -week and a 32-week rehabilitation programme after ACLR. They concluded that there were no differences in self-reported knee function, laxity, ROM, strength and hop tests at a 2-year follow-up. ${ }^{54} 55$ The rehabilitation programme of Muneta et $a l^{59}$ (level B) comprised a 6-month rehabilitation. Their results are comparable to both studies of Beynnon et al. 545559

The conclusions in this topic were as follows:

- Level 2: owing to a lack of high-quality studies and contradictory results, it is unclear whether there is a benefit of supervised rehabilitation compared to home-based rehabilitation or no rehabilitation at all. A minimally supervised rehabilitation programme may result in successful rehabilitation in specific groups of patients that are highly motivated and live far from a physical therapist. ${ }^{50} 525657$

- Level 2: when comparing a 19-week with a 32-week rehabilitation programme, there are no differences in terms of laxity, ROM, self-reported knee function, single-leg hop test for distance or isokinetic concentric quadriceps and HS strength. $^{54} 5559$

\section{OKC versus CKC quadriceps exercises}

Concerning the OKC and CKC quadriceps exercises, 11 articles were traced. These were four systematic reviews ${ }^{60-63}$ and seven RCTs. ${ }^{64-70}$

Andersson et $a l^{60}$ conclude in their systematic review (level A1) that after ACLR with BTPB, CKC quadriceps exercises produce less pain, less risk of increased laxity and better self-reported knee function compared to OKC quadriceps exercises. They included the RCTs of Bynum et al, ${ }^{64}$ Mikkelsen et al, ${ }^{67}$ Morrissey et al $l^{68}$ and Perry et $a l^{69}$ The recent RCT of Uçar $e t a l^{70}$ found no differences between CKC and OKC exercises, but they investigated a group of patients after ACLR with a HS graft.

The systematic reviews of Glass et al ${ }^{61}$ (level A1) and Wright et $a l^{63}$ (level A1) conclude that OKC quadriceps exercises 
should not be used in the first 6 weeks of rehabilitation after ACLR. Herewith, they confirmed the results of Andersson et al. ${ }^{60}$ The RCT of Heijne and Werner ${ }^{66}$ (level B) investigated early (4 weeks) versus late (12 weeks) start of OKC quadriceps exercises and compared ACLR with bone-patellar tendon-bone (BPTB) and HS. They concluded that the HS group with an early start had more laxity after a follow-up period of 7 months than the other groups. Besides, an early start of OKC quadriceps exercises had no beneficial effect on quadriceps strength. ${ }^{66}$ Fukuda et $a l^{65}$ (level B RCT) described that OKC quadriceps exercises can be started from week 4 after ACLR with HS, but in a limited ROM between $45^{\circ}$ and $90^{\circ}$.

The systematic review of Lobb et $a l^{62}$ concluded that there is limited evidence that a combination of OKC and CKC quadriceps exercises results in better strength and return to play than CKC exercises alone. They also included the systematic review of Andersson et al..$^{60} 61$

The overall conclusions were as follows:

- Level 1: CKC and OKC training can be used for regaining quadriceps strength. ${ }^{61} 6270$

- Level 2: after ACLR, OKC exercises can be performed from week 4 postoperative in a restricted ROM of 90$45^{\circ} .61636566$

\section{Strength training and neuromuscular training}

Concerning strength training and/or neuromuscular training, 21 articles were found. Among them were 3 systematic reviews ${ }^{71-73}$ and 18 RCTs. ${ }^{7-91}$

Systematic reviews of Gokeler $e t a l^{72}$ (level A1) and Kruse et $a l^{73}$ (level A1) concluded that eccentric quadriceps training can be safely incorporated 3 weeks after ACLR and may be the most effective way of restoring quadriceps strength. However, the level A1 systematic review of Augustsson ${ }^{71}$ concluded that the strength training programmes after ACLR should be further developed because it is still unclear what is the best way to train the quadriceps. To optimise outcome after rehabilitation, neuromuscular training should be added to strength training according to Gokeler et $a l^{72}$ and Kruse et al. ${ }^{73}$ Neuromuscular training is defined as training enhancing unconscious motor responses by stimulating afferent signals and central mechanisms responsible for dynamic joint control. ${ }^{92}$ These exercises are designed to induce compensatory changes in muscle activation patterns and facilitate dynamic joint stability. ${ }^{92}$ Nine RCTs were included in the above-mentioned systematic reviews: Cooper et al, ${ }^{78}$ Gerber et al, ${ }^{80}$ Gerber $e t$ al ${ }^{82}$ Risberg et al ${ }^{87}$ Risberg and Holm, ${ }^{88}$ Sekir et al ${ }^{89}$ and Shaw et al. ${ }^{90}$ The level B RCTs of Berschin et al, ${ }^{75}$ Bieler et al, ${ }^{76}$ Fu et al, ${ }^{79}$ Gerber $e t a l^{81}$ and Kinikli et $a l^{84}$ support the findings in those systematic reviews.

The level B RCTs of Isberg et $a l^{83}$ and Shaw et $a l^{90}$ concluded that isometric quadriceps exercises are safe in the first postoperative weeks, because there are no differences in laxity up to 2 years of follow-up.

Baltaci $e a^{74}$ (level B RCT) and Cappellino et $a l^{77}$ (level B RCT) demonstrated that the use of Wii Fit, respectively, neurocognitive rehabilitation have no beneficial effect to a combined strength and neuromuscular rehabilitation at a short-term follow-up.

Tyler et $a l^{91}$ (level B RCT) concluded that immediate weight bearing had no detrimental effects for laxity and a positive effect on anterior knee pain at a 1-year follow-up.

The main conclusions were as follows:

- Level 1: starting eccentric quadriceps training (in CKC) from 3 weeks after ACLR is safe and contributes to a bigger improvement in quadriceps strength than concentric training. ${ }^{72} 73768184$

- Level 1: neuromuscular training should be added to strength training to optimise self-reported outcome measurements. ${ }^{72} 737579$

- Level 2: isometric quadriceps exercises are safe from the first postoperative week. ${ }^{83} 90$

- Level 3: immediate weight bearing does not affect knee laxity and results in decreased incidence of anterior knee pain. $^{91}$

\section{Electrostimulation and electromyographic feedback}

Eleven articles about electrostimulation and electromyographic feedback were found. These were four systematic reviews, ${ }^{63} 93-95$ six RCTs ${ }^{9-101}$ and one prospective cohort study. ${ }^{102}$

Imoto $e$ t $a l^{93}$ and Kim et $a l^{94}$ (level A1 systematic reviews) concluded that the addition of electrostimulation to conventional rehabilitation might be more effective in improving quadriceps strength up to 2 months after ACLR. The level A2 RCT of Paternostro-Sluga et $a l^{100}$ and the level B RCT of Fitzgerald et al $^{99}$ were included in both systematic reviews. Ediz et $a l^{97}$ (level B RCT) and Lepley et $a l^{102}$ (level C prospective cohort study) found no differences in effusion, pain, ROM and knee extension and flexion moments when electrostimulation was added to conventional rehabilitation. Feil et $a l^{98}$ and Taradaj et $a l^{101}$ (both level B RCTs) did examine quadriceps strength and found a higher increase in quadriceps strength when electrostimulation was added to conventional rehabilitation at a 6-month follow-up. Wright et al ${ }^{63}$ (level A1 systematic review) summarised that electrostimulation may help improve quadriceps strength in the early postoperative period, but that it is not a prerequisite for successful rehabilitation. All authors did not distinguish between regaining quadriceps motor control and increasing quadriceps strength.

Studies concerning electromyographic feedback are contradictory. The systematic review of Wasielewski et $a l^{95}$ (level A1) showed that electromyographic feedback improves short-term postsurgical pain after ACLR, but Christanell et al ${ }^{96}$ (level B RCT) described no differences in pain during the first six postoperative weeks with or without biofeedback.

The conclusions on this topic were as follows:

- Level 1: electrostimulation, in combination with conventional rehabilitation, might be more effective for improving muscle strength for up to 2 months after ACLR than conventional rehabilitation alone. However, its effect on long-term functional performance and self-reported knee function is inconclusive. 63939498101

- Level 2: electromyographic feedback might improve shortterm postsurgical pain after ACLR. ${ }^{95} 96$

\section{Cryotherapy}

Five articles were found about cryotherapy: two meta-analyses, ${ }^{103} 104$ one systematic review, ${ }^{105}$ one RCT $^{106}$ and one prospective cohort study. ${ }^{107}$

All three level A1 articles shared the conclusion that cryotherapy is effective in reducing postoperative pain until about 1 week postsurgery, but it has no effect on drainage or ROM. ${ }^{103-105}$ The level A2 RCT of Edwards et al ${ }^{106}$ was included in the meta-analyses of Martimbianco et al. ${ }^{103}$ The prospective cohort study of Glenn et al ${ }^{107}$ (level C) supports these findings.

The conclusion on this topic was as follows:

- Level 1: cryotherapy is effective in decreasing pain immediately after application up to 1 week postsurgery after 
ACLR, but has no effect on postoperative drainage or ROM. ${ }^{103-105} 107$

\section{Measurements of functional performance}

Eight articles about measurements of functional performance were traced: six systematic reviews ${ }^{23} 27281^{108-110}$ and two prospective cohort studies. ${ }^{111} 112$

Five systematic reviews (all level B) concluded that there is a lack of objective criteria to determine return to play. $^{23} 27 \quad 28 \quad 109110$ Extensive test batteries for determining quantity and quality of movement are recommended, including strength tests, hop tests and video analysis for measuring quality of movement. ${ }^{27} 28$

There is weak evidence from a level A2 systematic review for factors that could be associated with a higher chance of return to play: less effusion, less pain, higher quadriceps strength, greater tibial rotation, higher Marx Scale score, higher athletic confidence, higher preoperative knee self-efficacy, lower kinesiophobia and higher preoperative self-motivation. ${ }^{108}$ Müller et $a l^{111}$ (level B prospective cohort study) added better selfreported knee function and better hop test performance to this list.

Thomeé et $a l^{112}$ (level B prospective cohort study) described that there were poor results at 2 years after ACLR when testing leg muscle power and hop performance and applying an Limb Symmetry Index (LSI) of $>90 \%$ to all six tests. Only $23 \%$ of patients passed when using these criteria and only $10 \%$ passed when an LSI of $95 \%$ was used. ${ }^{112}$

The overall conclusions were as follows:

- Level 2: an extensive test battery should be used for determining the moment for return to play, but there are no tests or test batteries that have been tested for construct or predictive validity for return to play. ${ }^{23} 2728$ 108-111

- Level 3: It is not clear which cut-off point of the LSI should be used for strength and hop tests. ${ }^{112}$

\section{Return to play}

Ten articles were traced about return to play: two meta-analyses, ${ }^{13}{ }^{14}$ two systematic reviews ${ }^{113} 114$ and six prospective cohort studies. ${ }^{17} 22$ 115-118

The meta-analysis of Ardern et al ${ }^{13}$ (level A2) included their earlier meta-analysis ${ }^{14}$ and the prospective cohort studies of Brophy et al, ${ }^{17}$ Gobbi and Francisco ${ }^{115}$ and Langford et al. ${ }^{22}$ They found that $65 \%$ of patients after ACLR returned to preinjury competitive sport level within 2 years, but only $38 \%$ remained at the same level $>2$ years after ACLR. Men were 1.4 times more likely to return to their preinjury sport level than women, and BPTB was 1.2 times more likely than HS. $^{13} 141722115$ Laboute et al ${ }^{116}$ (level C prospective cohort study) reported $65.7 \%$ of athletes returning to preinjury sport level, while Zaffagnini et al ${ }^{118}$ reported a higher return to preinjury sport level of $71 \%$ in a group of professional soccer players 4 years after ACLR.

Several psychological factors have influence on the rehabilitation process and return to play. According to the systematic reviews of Everhart et al ${ }^{113}$ (level A2) and te Wierike et al ${ }^{114}$ (level B), a high self-efficacy, a high internal locus of control and a low level of fear are associated with a higher chance of return to play. They included the prospective cohort studies of Gobbi and Francisco, ${ }^{115}$ Langford et $a l^{22}$ and Thomeé et al. ${ }^{117}$

The literature concluded that:

- Level 1: the rate of return to preinjury play level for (nonprofessional) pivoting athletes after ACLR is 65\%. ${ }^{13} 116$
- Level 2: Psychological factors as self-efficacy, locus of control and fear of reinjury have influence on the rehabilitation process and return to play after ACLR. ${ }^{113} 114$

\section{Risk of reinjuries}

Five articles about risk of reinjuries were found. These were two systematic reviews ${ }^{119}{ }^{120}$ and three prospective cohort studies. $^{293536}$

The systematic reviews of Swärd et $a l^{119}$ and Wright et al $l^{120}$ (both level B) concluded that the risk of a contralateral ACL injury is higher than the risk of a first-time ACL rupture or an ACL graft rerupture. The level B prospective cohort study of Wright et $a l^{29}$ was included in both systematic reviews.

The level B prospective cohort studies of Hewett et $a l^{35}$ and Paterno $e t a l^{36}$ support the conclusions of the systematic review of Swärd et $a l^{119}$ that altered neuromuscular function and biomechanics could be responsible for the risk of second ACL rupture (graft rerupture and contralateral ACL). Factors contributing could be greater hip internal rotation, the occurrence of dynamic knee valgus or less knee flexion when landing from a jump. ${ }^{35} 36119$

Their conclusions were as follows:

- Level 2: the risk of a contralateral ACL rupture $(>10 \%)$ is higher than the risk of graft rerupture (about 5\%) (up to 10 years after ACLR) or first-time ACL rupture. ${ }^{119} 120$

- Level 2: altered neuromuscular function and biomechanics (greater hip internal rotation, the occurrence of dynamic knee valgus or less knee flexion during landing) after ACLR could be a risk factor for second ACL injury (graft rerupture or contralateral rupture). ${ }^{35} 36119$

\section{CONSENSUS CONCLUSION}

Although there are many articles published about ACL rehabilitation, there is limited evidence for parameters that influence or predict the final result of ACLR rehabilitation and return to play. The aim of this study was to describe the process in which the KNGF evidence statement for ACL rehabilitation was developed and to present this practice guideline (see online supplementary appendix 2). The goal of the evidence statement was to describe the rehabilitation after ACLR with BPTB or HS autograft and to encourage uniformity in physical therapy treatment and the use of measurements of functional performance. The evidence statement is aimed to fill a gap between evidence and clinical practice and describes a complete protocol to rehabilitate an athlete after ACLR. The multidisciplinary approval of this evidence statement underlines the importance of a close collaboration between different professions.

Despite the fact that our evidence statement is based on information from RCTs and systematic reviews from the two most important databases, the evidence is inconclusive. Owing to this lack of scientific evidence, available background literature and a steering group consisting of ACL experts were used to develop a multidisciplinary consensus statement for an ACLR rehabilitation protocol. This consensus statement was based on three formulated questions with the following conclusions.

\section{What should be the content of the rehabilitation protocol after ACLR?}

The description of the rehabilitation protocol is divided into preoperative and postoperative rehabilitation.

Preoperative rehabilitation

Preoperative rehabilitation, also known as prehabilitation, is not usually prescribed by orthopaedic surgeons (or trauma surgeons) in the Netherlands. Previous studies showed that a preoperative 
full extension ROM reduces the chance for postoperative complications as arthrofibrosis. ${ }^{46}{ }^{48}$ Moreover, a deficit in quadriceps strength of $20 \%$ or more predicts a significant strength deficit until 2 years after ACLR (level 2). ${ }^{41}{ }^{121}$ Therefore, the steering group recommends to measure the preoperative ROM and quadriceps strength as part of the preoperative rehabilitation protocol. The steering group also advises to measure HS strength, although there is no recommendation for HS measurement in literature. Yet, there are studies that conclude that HS strength in the operated leg is still reduced compared to the non-operated leg until 2 years after ACLR. ${ }^{121}$ For this examination and possible treatment, the patient could be referred to a physical therapist to prevent a complicated or prolonged rehabilitation.
Preoperative information about walking with crutches, the early postoperative exercises and the rehabilitation process may improve a patients' self-efficacy; thus, the steering group advises to discuss these topics with patients (level 4). See also table 6 for a summary of conclusions and recommendations.

\section{Postoperative rehabilitation}

Good communication between the surgeon and physical therapist is of great importance. While the orthopaedic surgeon is responsible for the surgery results and techniques, the physical therapist should be leading in decision-making in rehabilitation. Therefore, the steering group advises that the orthopaedic surgeon (or trauma surgeon) informs the physical therapist about perioperative findings: graft type, menisectomy or

Table 6 Summary of conclusions and recommendations

Conclusions and recommendations

Preoperative rehabilitation

A preoperative extension deficit (lack of full extension) is a major risk factor for an extension deficit after ACLR

Recommendation: measure the preoperative ROM

A preoperative deficit in quadriceps strength of $>20 \%$ has a significant negative consequence for the self-reported outcome 2 years after ACLR

Recommendation: measure quadriceps strength and also HS strength

Prehabilitation ensures better self-reported knee function up to 2 years after ACLR

Recommendation: refer the patient to a physical therapist when necessary

\section{Postoperative rehabilitation}

It is unclear whether there is a benefit of supervised rehabilitation compared to home-based rehabilitation or no rehabilitation at all. A minimally supervised rehabilitation programme may result in successful rehabilitation in specific groups of patients that are highly motivated and live far from a physical therapist When comparing a 19-week with a 32-week rehabilitation programme, there are no differences in terms of laxity, ROM, self-reported knee function, single-leg hop test for distance or isokinetic concentric quadriceps and HS strength

Recommendation: continue rehabilitation for 9-12 months, depending on the final return-to-work or play goals of the patient

Immediate weight bearing does not affect knee laxity and results in decreased incidence of anterior knee pain

Recommendation: immediate weight bearing should only be tolerated if there is a correct gait pattern (if necessary with crutches) and no pain, effusion or increase in temperature when walking or shortly after walking

Cryotherapy is effective in decreasing pain immediately after application up to 1 week postsurgery after ACLR, but has no effect on postoperative drainage or ROM

Recommendation: cryotherapy could eventually be applied in the first postoperative week to reduce pain

Isometric quadriceps exercises are safe from the first postoperative week

Recommendation: start isometric quadriceps exercises in this first week for reactivating the quadriceps muscles when they provoke no pain

Electrostimulation, in combination with conventional rehabilitation, might be more effective for improving muscle strength for up to 2 months after ACLR than conventional rehabilitation alone. However, its effect on long-term functional performance and self-reported knee function is inconclusive.

Recommendation: electrostimulation can be useful as an addition to isometric strength training for re-educating voluntary contraction of the quadriceps muscles during the first postoperative weeks

CKC and OKC training can be used for regaining quadriceps strength

After ACLR, OKC exercises can be performed from week 4 postoperative in a restricted ROM of $90-45^{\circ}$

Recommendation: When the quadriceps is reactivated, concentric and eccentric exercises should be used to replace the isometric exercises, provided that the knee does not react with effusion or (an increase in) pain. CKC exercises can be performed from week 2 postoperative. For BPTB, OKC exercises can be started from 4 weeks postoperative in a restricted ROM of $90-45^{\circ}$ and extra resistance is allowed, for example, at a leg extension machine. For HS, OKC exercises also can be started from 4 weeks postoperative in a restricted ROM of 90-45, but no extra weight should be added in the first 12 weeks to prevent graft elongation ROM can be increased to $90-30^{\circ}$ in week 5 , to $90-20^{\circ}$ in week 6 , to $90-10^{\circ}$ in week 7 and to full ROM in week 8 for both graft types

Neuromuscular training should be added to strength training to optimise self-reported outcome measurements

Altered neuromuscular function and biomechanics after ACLR could be a risk factor for second ACL injury (graft rerupture or contralateral rupture)

Recommendation: neuromuscular training should be added to strength training. Pay attention to a correct quality of movement for prevention of reinjuries

Psychological factors as self-efficacy, locus of control and fear of reinjury have influence on the rehabilitation process and return to play after ACLR

Recommendation: evaluate psychological changes during rehabilitation with an objective instrument

\section{Criteria for return to play}

An extensive test battery should be used to determine the return-to-play moment, but there are no tests or test batteries that have been tested for construct or predictive validity for return to play

It is not clear which cut-off point of the LSI should be used for strength and hop tests

Recommendation: perform an extensive test battery for quantity and quality of movement. This test battery should include at least a strength test battery and a hop test battery and measurement of quality of movement. An LSI of $>90 \%$ could be used as a cut-off point. For pivoting/contact sports, an LSI of $\geq 100 \%$ is recommended 
meniscus repair, cartilage damage (location, size and grade), ligamentous injuries or complications during surgery. Also, when possible in his setting, the physical therapist should inform the surgeon about the current status of the patient preceding to every preoperative or postoperative outpatient appointment, to ensure that appropriate levels of stress are being applied to the healing tissues. ${ }^{122}$

During the first meeting of the working and steering group, it was decided to define different phases during rehabilitation after ACLR. Current literature describes time-based rehabilitation protocols that are mainly based on the remodelling process of the graft. ${ }^{51}$ Since there is still uncertainty about the time schedule of the human remodelling process, it makes more sense to incorporate functional goal-based criteria to the rehabilitation protocol. ${ }^{123-126}$ Besides, there are individual differences in neuromotor learning and flexibility after ACLR. These underline the importance of a shift from time-based rehabilitation to goal-based rehabilitation with neuromuscular goals and criteria to manage the rehabilitation process. These goals for progression to the next phase and description of interventions during each phase are based on the International Classification of Functioning, Disability and Health (WHO 2001). Our evidence statement consists of three phases (see online supplementary appendix 2) with a goal-based progression: the so-called traffic-light method of progression through phases. This is relatively new in rehabilitation, but it assures a more patient-tailored rehabilitation. ${ }^{118}{ }^{127}$ Patients can start with the next phase only if specific goals of the previous phase are achieved and these should be confirmed with objective tests (see online supplementary appendix 2 for criteria).

The steering group advises to start rehabilitation immediate after ACLR and continue rehabilitation for 9-12 months, depending on the final return-to-work or play goals of the patient. ${ }^{128}$ This rehabilitation period is necessary to allow return to high-intensity sport or physically demanding work. This term differs from a previous ACLR rehabilitation protocol by van Grinsven $e t a l,{ }^{51}$ who presented a 22 -week rehabilitation with four time-based phases. Recent evidence suggests that longer rehabilitation periods are needed, because most patients are not able to reach the end-rehabilitation goals in 22 weeks. ${ }^{129} 130$ Herbst $e t$ al ${ }^{131}$ presented a new functional performance test battery and concluded that most patients were not ready for return to play even at 8 months after ACLR. Others suggest that home-based rehabilitation is as effective as supervised rehabilitation. ${ }^{53} 5657$ These home-based rehabilitation programmes are designed in countries where patients live too far from a physical therapist to schedule a visit a few times in a week. Important to mention is that these programmes are not designed for patients who perform high-intensity sports. Still, there is no evidence which rehabilitation period or how many appointments per week works best for return to play.

During postoperative rehabilitation, a physical therapist can use several treatment modalities, of which some are proven to be effective in literature and some are not (table 6). It is known that immediate weight bearing is safe (level 3). ${ }^{91}$ The steering group recommends that immediate weight bearing should only be tolerated if there is a correct gait pattern (if necessary with crutches) and no pain, effusion or increase in temperature when walking or shortly after walking. Cryotherapy could eventually be applied in the first postoperative week to reduce pain (level 1). ${ }^{103-107}$ The steering group suggests to start isometric quadriceps exercises in this first week for reactivating the quadriceps muscles when they provoke no pain (level 2). ${ }^{83} 90$ In addition, electrostimulation can be useful for re-educating voluntary contraction of the quadriceps muscles during the first postoperative weeks (level 1). ${ }^{63} 939498-101$ When the quadriceps is reactivated, concentric and subsequently eccentric exercises should be used to replace the isometric exercises, provided that the knee does not react with effusion or (an increase in) pain. Quadriceps strength training can be performed in CKC and OKC. Concentric CKC exercises can be performed from week 2 postoperative. For OKC exercises, there should be a distinction between ACLR with a BPTB graft or a HS graft. For BPTB, OKC exercises can be started from 4 weeks postoperative in a restricted ROM of $90-45^{\circ}$ and extra resistance is allowed, for example, at a leg extension machine (level 2). For HS, OKC exercises can also be started from 4 weeks postoperative in a restricted ROM of $90-45^{\circ}$, but no extra weight should be added in the first 12 weeks to prevent graft elongation (level 2). ${ }^{65} 66$ ROM can be increased to $90-30^{\circ}$ in week 5 , to $90-20^{\circ}$ in week 6 , to $90-10^{\circ}$ in week 7 and to full ROM in week 8 for both graft types. ${ }^{51}$ The steering group strongly advises that neuromuscular training should be added to strength training to optimise outcome measurements (level 1). $.^{72} 737578798587-90$

In literature about rehabilitation after ACLR, there is a lack of focus on the evaluation and training of the quality of movement as measurement of neuromuscular recovery. The relevance to focus more on the quality of movement is underlined by the fact that altered neuromuscular function and biomechanics after ACLR could be a risk factor for a second ACL injury (level 2). ${ }^{35} 36119$ An improvement in quality of movement can be observed as an effect of motor learning. In the early phases of rehabilitation, mostly explicit motor learning is necessary, but we advocate that in the late phase of rehabilitation, more implicit motor learning strategies should be used. ${ }^{132}$ This is because implicit learning may produce more stable solutions under stress, anxiety-provoking conditions and fatigue states, especially necessary in sports. ${ }^{130}$

\section{Which measurements and assessments can be applied to monitor progression during the rehabilitation programme and to determine outcomes at the end of rehabilitation programme?}

There are no clear recommendations regarding the use of measurements for quantity (eg, strength and hop performance) and quality of movement during the postoperative rehabilitation process. The criteria to progress from phase 1 to phase 2 or from phase 2 to phase 3 are based on expert opinion (see online supplementary appendix 2). Besides the quantity and quality of movement, it is important to evaluate psychological changes during rehabilitation with an objective instrument, for example, with the Marx Scale, the Psychovitality Scale or the Knee Self-Efficacy Scale (level 2). ${ }^{22} 108$ 113-115 117

\section{What criteria should be used to determine the moment of return to play?}

All included systematic reviews about measurements of functional performance have the same conclusion: studies are lacking objective physiological criteria at what time after ACLR return to play is allowed. ${ }^{27} 3132108-110$ There is also no conclusive evidence that any test or test battery can accurately identify athletes at high risk of reinjury. Therefore, the steering group recommends to perform an extensive test battery for quantity and quality of movement (level 2). ${ }^{27} 31 \quad 32$ 108-111 This test battery should include at least a strength test battery and a hop test battery and measurement of quality of movement for 
determining the moment for return to play. An LSI of $>90 \%$ could be used as a cut-off point. For pivoting/contact sports, an LSI of $\geq 100 \%$ is recommended (see online supplementary appendix 2). ${ }^{133}$ Qualitative scoring systems as the Jump Landing System and Landing Error Scoring System have been developed in the past few years, but it is still unclear in which manner quality of movement plays a role in the occurrence of ACL reinjuries. ${ }^{134-138}$ Therefore, prospective studies are needed to evaluate whether these scoring systems are able to measure neuromotor control and to investigate the predictive validity of those qualitative scoring systems.

\section{LIMITATIONS}

Meta-analyses and systematic reviews were included in this study. A strength is the additional weight in evidence, but a limitation is that the included meta-analyses and systematic reviews may have used other inclusion and exclusion criteria than the ones used in this study. The main discrepancy is that they did not mention the graft choice or brace-free rehabilitation in their information. We accept this limitation because many meta-analyses and systematic reviews are written about rehabilitation after ACLR and they comprise the highest level of evidence. In most cases, they give useful advice for day-to-day clinical practice and add value to the included RCTs and prospective cohort studies.

Despite the extensive literature search, our recommendations are lacking a certain specificity regarding sets, repetitions and resistance used in exercises. This is because included studies are vague in describing these parameters. However, it is extremely difficult to describe this for a population of patients, because these parameters depend on pain, effusion and level of the patient (eg, concerning type of sport and experience with strength training). We expect that every sports physical therapist is able to address the correct parameters to his individual patient, but suggest that more research is needed on this topic.

\section{What are the findings?}

- Rehabilitation after anterior cruciate ligament reconstruction should consist of three phases, which are goal-based rather than time-based. The goals for progression to the next phase and description of interventions during each phase should be based on the International Classification of Functioning, Disability and Health.

- An extensive test battery, including at least a strength test battery, a hop test battery and measurement of quality of movement, is needed to determine the moment of return to play.

\section{How might it impact on clinical practice in the future?}

- Thirty-five per cent of athletes after anterior cruciate ligament reconstruction (ACLR) do not return to preinjury sport level within 2 years.

- Closed and open kinetic chain quadriceps training can be used for regaining strength, but neuromuscular training should be added to strength training to optimise outcome measurements after ACLR.

- Movement quality may affect the ACL (re)injury rate.
Twitter Follow Nicky van Melick@KneeSearch

Acknowledgements The authors appreciate the tremendous efforts of Erik Hendriks in the working group. The authors thank the steering group (M. Antvelink, P.A. van Beek, M. Eskes, R.P.A. Janssen, A.F. Lenssen and Th.P.H. van Thiel), and the KNGF for their contributions in realising the evidence statement.

Funding The realisation of the KNGF evidence statement was funded by the KNGF. Competing interests None declared.

Provenance and peer review Not commissioned; externally peer reviewed.

\section{REFERENCES}

1 Prodromos CC, Han Y, Rogowski J, et al. A meta-analysis of the incidence of anterior cruciate ligament tears as a function of gender, sport, and a knee injury-reduction regimen. Arthroscopy 2007;23:1320-5.

2 Moses B, Orchard J, Orchard J. Systematic review: annual incidence of ACL injury and surgery in various populations. Res Sports Med 2012;20:157-79.

$3 \mathrm{Yoo} \mathrm{JH}$, Lim BO, Ha M, et al. A meta-analysis on the effect of neuromuscular training on the prevention of the anterior cruciate ligament injury in female athletes. Knee Surg Sports Traumatol Arthrosc 2010;18:824-30.

4 Hewett TE, Zazulak BT, Myer GD, et al. A review of electromyographic activation levels, timing differences, and increased anterior cruciate ligament injury incidence in female athletes. Br J Sports Med 2005;39:347-50.

5 Lephart SM, Ferris CM, Fu FH. Risk factors associated with noncontact anterior cruciate ligament injuries in female athletes. Instr Course Lect 2002; 51:307-10.

6 Toth AP, Cordasco FA. Anterior cruciate ligament injuries in the female athlete. $J$ Gend Specif Med 2001;4:25-34.

7 Huston LJ, Greenfield ML, Wojtys EM. Anterior cruciate ligament injuries in the female athlete. Potential risk factors. Clin Orthop Relat Res 2000:50-63.

8 Myer GD, Sugimoto D, Thomas S, et al. The influence of age on the effectiveness of neuromuscular training to reduce anterior cruciate ligament injury in female athletes: a meta-analysis. Am J Sports Med 2013;41:203-15.

9 Zimmy ML, Schutte M, Dabezies E. Mechanoreceptors in the human anterior cruciate ligament. Anat Rec 1986;214:204-9.

10 Decker LM, Moraiti C, Stergiou N, et al. New insights into anterior cruciate ligament deficiency and reconstruction through the assessment of knee kinematic variability in terms of nonlinear dynamics. Knee Surg Sports Traumatol Arthrosc 2011;19:1620-33.

11 Courtney CA, Rine RM. Central somatosensory changes associated with improved dynamic balance in subjects with ACL deficiency. Gait Posture 2006;24:190-5.

12 Kapreli E, Athanasopoulos S, Gliatis J, et al. ACL deficiency causes brain plasticity: a functional MRI study. Am J Sports Med 2009;37:2419-26.

13 Ardern CL, Taylor NF, Feller JA, et al. Fifty-five percent return to competitive sport following anterior cruciate ligament surgery: an updated systematic review and meta-analysis including aspects of physical functioning and contextual factors. $\mathrm{Br}$ J Sports Med 2014;48:1543-52.

14 Ardern $\mathrm{CL}$, Webster $\mathrm{KE}$, Taylor NF, et al. Return to sport following anterior cruciate ligament reconstruction surgery: a systematic review and meta-analysis of the state of play. Br J Sports Med 2011;45:596-606.

15 Shah VM, Andrews JR, Fleisig GS, et al. Return to play after anterior cruciate ligament reconstruction in National Football League athletes. Am J Sports Med 2010;38:2233-9.

16 Ardern CL, Taylor NF, Feller JA, et al. Return-to-sport outcomes at 2 to 7 years after anterior cruciate ligament reconstruction surgery. Am J Sports Med 2012;40:41-8.

17 Brophy RH, Schmitz L, Wright RW, et al. Return to play and future $A C L$ injury risk after $A C L$ reconstruction in soccer athletes from the Multicenter Orthopaedic Outcomes Network (MOON) group. Am J Sports Med 2012;40:2517-22.

18 McCullough KA, Phelps KD, Spindler KP, et al. Return to high school- and college-level football after anterior cruciate ligament reconstruction: a Multicenter Orthopaedic Outcomes Network (MOON) cohort study. Am J Sports Med 2012;40:2523-9.

19 Kvist J, Ek A, Sporrstedt K, et al. Fear of re-injury: a hindrance for returning to sports after anterior cruciate ligament reconstruction. Knee Surg Sports Traumatol Arthrosc 2005; 13:393-7.

20 Chmielewski TL, Jones D, Day $T$, et al. The association of pain and fear of movement/reinjury with function during anterior cruciate ligament reconstruction rehabilitation. J Orthop Sports Phys Ther 2008;38:746-53.

21 Webster KE, Feller JA, Lambros C. Development and preliminary validation of a scale to measure the psychological impact of returning to sport following anterior cruciate ligament reconstruction surgery. Phys Ther Sport 2008;9:9-15.

22 Langford JL, Webster KE, Feller JA. A prospective longitudinal study to assess psychological changes following anterior cruciate ligament reconstruction surgery. Br J Sports Med 2009;43:377-81.

23 Ardern $\mathrm{CL}$, Webster KE, Taylor NF, et al. Return to the preinjury level of competitive sport after anterior cruciate ligament reconstruction surgery: two-thirds of patients have not returned by 12 months after surgery. Am J Sports Med 2011;39:538-43. 
24 Ardern CL, Taylor NF, Feller JA, et al. Psychological responses matter in returning to preinjury level of sport after anterior cruciate ligament reconstruction surgery. Am J Sports Med 2013;41:1549-58.

25 Flanigan DC, Everhart JS, Pedroza A, et al. Fear of reinjury (kinesiophobia) and persistent knee symptoms are common factors for lack of return to sport after anterior cruciate ligament reconstruction. Arthroscopy 2013;29:1322-9.

26 Ahldén M, Samuelsson K, Sernert N, et al. The Swedish National anterior cruciate ligament register. A report on baseline variables and outcomes of surgery for almost 18,000 patients. Am J Sports Med 2012;40:2230-5.

27 Barber-Westin SD, Noyes FR. Objective criteria for return to athletics after anterior cruciate ligament reconstruction and subsequent reinjury rates: a systematic review. Phys Sportsmed 2011;39:100-10.

28 Paterno MV, Rauh MJ, Schmitt LC, et al. Incidence of contralateral and ipsilateral anterior cruciate ligament $(\mathrm{ACL})$ injury after primary $\mathrm{ACL}$ reconstruction and return to sport. Clin J Sport Med 2012;22:116-21.

29 Wright RW, Dunn WR, Amendola A, et al. Risk of tearing the intact anterior cruciate ligament in the contralateral knee and rupturing the anterior cruciate ligament graft during the first 2 years after anterior cruciate ligament reconstruction. A prospective MOON cohort study. Am J Sports Med 2007;35:1131-13.

30 The Swedish National ACL Register. Annual report 2011. http://www.aclregister.nu

31 Barber-Westin SD, Noyes FR. Factors used to determine return to unrestricted sports activities after anterior cruciate ligament reconstruction. Arthroscopy 2011;27:1697-705.

32 Engelen-van Melick N, van Cingel REH, Tijssen MPW, et al. Assessment of functional performance after anterior cruciate ligament reconstruction: a systematic review of measurement procedures. Knee Surg Sports Traumatol Arthrosc 2013:21:869-79.

33 Renstrom $P$, Ljungqvist $A$, Arendt $E$, et al. Non-contact $A C L$ injuries in female athletes: an International Olympic Committee current concepts statement. $\mathrm{Br}$ J Sports Med 2008;42:394-412.

34 Padua DA, DiStefano LJ, Beutler Al, et al. The landing error scoring system as a screening tool for an anterior cruciate ligament injury-prevention program in elite-youth soccer athletes. J Athl Train 2015;50:589-95.

35 Hewett TE, Myer GD, Ford KR, et al. Biomechanical measures of neuromuscular control and valgus loading of the knee predict anterior cruciate ligament injury risk in female athletes. A prospective study. Am J Sports Med 2005;33:492-501.

36 Paterno MV, Schmitt LC, Ford KR, et al. Biomechanical measures during landing and postural stability predict second anterior cruciate ligament injury after anterior cruciate ligament reconstruction and return to sport. Am J Sports Med 2010;38:1968-78

37 Vereniging NTvG. EBRO richtlijnen. Ned Tijdschr Geneesk 2005;149:213-4.

38 Bernards ATM, Berghmans LCM, Van Heeswijk-Faase IC, et al. KNGF richtlijn Stress (urine)incontinentie. Ned Tijdschr Fysiother 2011;121(Suppl):1-23.

39 Kerkhoffs GM, van den Bekerom M, Elders LAM, et al. Diagnosis, treatment and prevention of ankle sprains: an evidence-based clinical guideline. $\mathrm{Br}$ J Sports Med 2012;46:854-60.

40 de Valk EJ, Moen MH, Winters $M$, et al. Preoperative patient and injury factors of successful rehabilitation after anterior cruciate ligament reconstruction with single-bundle techniques. Arthroscopy 2013;29:1879-95.

41 Shaarani SR, O'Hare C, Quinn A, et al. Effect of prehabilitation on the outcome of anterior cruciate ligament reconstruction. Am J Sports Med 2013;41:2117-27.

42 Eitzen I, Holm I, Risberg MA. Preoperative quadriceps strength is a significant predictor of knee function two years after anterior cruciate ligament reconstruction. Br J Sports Med 2009;43:371-6.

43 Grindem H, Granan LP, Risberg MA, et al. How does a combined preoperative and postoperative rehabilitation programme influence the outcome of $\mathrm{ACL}$ reconstruction 2 years after surgery? A comparison between patients in the Delaware-Oslo ACL Cohort and the Norwegian National Knee Ligament Registry. Br J Sports Med 2015;49:385-9.

44 Heijne A, Äng BO, Werner S. Predictive factors for 12-month outcome after anterior cruciate ligament reconstruction. Scand J Sci Med Sports 2009;19: 842-9.

45 Lepley LK, Palmieri-Smith RM. Pre-operative quadriceps is related to post-operative activation, not strength, in patients post- $\mathrm{ACL}$ reconstruction. Knee Surg Sports Traumatol Arthrosc 2016;24:236-46.

46 Månsson 0 , Kartus J, Sernert N. Pre-operative factors predicting good outcome in terms of health-related quality of life after ACL reconstruction. Scand J Med Sci Sports 2013;23:15-22.

47 McHugh MP, Tyler TF, Gleim GW, et al. Preoperative indicators of motion loss and weakness following anterior cruciate ligament reconstruction. J Orthop Sports Phys Ther 1998:27:407-11.

48 McHugh MP, Tyler TF, Browne MG, et al. Electromyographic predictors of residual quadriceps muscle weakness after anterior cruciate ligament reconstruction. Am J Sports Med 2002;30:334-9.

49 Quelard B, Sonnery-Cottet B, Zayni R, et al. Preoperative factors correlating with a prolonged range of motion deficit after anterior cruciate ligament reconstruction. Am J Sports Med 2010;38:2034-9.
50 Coppola SM, Collins SM. Is physical therapy more beneficial than unsupervised home exercise in treatment of post surgical knee disorders? A systematic review. Knee 2009;16:171-5.

51 van Grinsven S, van Cingel RE, Holla CJ, et al. Evidence-based rehabilitation following anterior cruciate ligament reconstruction. Knee Surg Sports Traumatol Arthrosc 2010;18:1128-44.

52 Wright RW, Preston, E, Fleming BC, et al. A systematic review of anterior cruciate ligament reconstruction rehabilitation. Part I: continuous passive motion, early weight bearing, postoperative bracing, and home-based rehabilitation. I Knee Surg 2008;21:217-24.

53 Beard DJ, Dodd CAF. Home or supervised rehabilitation following anterior cruciate ligament reconstruction: a randomized controlled trial. J Orthop Sports Phys Ther 1998:27:134-43.

54 Beynnon BD, Uh BS, Johnson RJ, et al. Rehabilitation after anterior cruciate ligament reconstruction. A prospective, randomized, double-blind comparison of programs administered over 2 different time intervals. Am J Sports Med 2005;33:347-59.

55 Beynnon BD, Johnson RJ, Naud S, et al. Accelerated versus nonaccelerated rehabilitation after anterior cruciate ligament reconstruction. A prospective, randomized, double-blind investigation evaluating knee joint laxity using roentgen stereophotogrammetric analysis. Am J Sports Med 2011;39:2536-48.

56 Grant JA, Mohtadi NGH. Two- to 4-year follow-up to a comparison of home versus physical therapy-supervised rehabilitation programs after anterior cruciate ligament reconstruction. Am J Sports Med 2010;38:1389-94.

57 Hohmann E, Tetsworth K, Bryant A. Physiotherapy-guided versus home-based, unsupervised rehabilitation in isolated anterior cruciate injuries following surgical reconstruction. Knee Surg Sports Traumatol Arthrosc 2011;19:1158-67.

58 Dragicevic-Cvjetkovic D, Jandric S, Bijeljac $S$, et al. The effects of rehabilitation protocol on functional recovery after anterior cruciate ligament reconstruction. Med Arch 2014;68:350-2

59 Muneta T, Sekiya I, Ogiuchi T, et al. Effects of aggressive early rehabilitation on the outcome of anterior cruciate ligament reconstruction with multi-strand semitendinosus tendon. Int Orthop 1998:22:352-6.

60 Andersson D, Samuelsson K, Karlsson J. Treatment of anterior cruciate ligament injuries with special reference to surgical technique and rehabilitation: an assessment of randomized controlled trials. Arthroscopy 2009;25:653-85.

61 Glass R, Waddell J, Hoogenboom B. The effects of open versus closed kinetic chain exercises on patients with $\mathrm{ACL}$ deficient or reconstructed knees: a systematic review. N Am J Sports Phys Ther 2010;5:74-84.

62 Lobb R, Tumilty $S$, Claydon LS. A review of systematic reviews on anterior cruciate ligament reconstruction. Phys Ther Sport 2012;13:270-8.

63 Wright RW, Preston E, Fleming BC, et al. A systematic review of anterior cruciate ligament reconstruction rehabilitation. Part II: open versus closed kinetic chain exercises, neuromuscular electrical stimulation, accelerated rehabilitation, and miscellaneous topics. J Knee Surg 2008;21:225-34.

64 Bynum EB, Barrack RL, Alexander AH. Open versus closed chain kinetic exercises after anterior cruciate ligament reconstruction. A prospective randomized study. Am J Sports Med 1995:23:401-6.

65 Fukuda TY, Fingerhut D, Coimbra Moreira V, et al. Open kinetic chain exercises in a restricted range of motion after anterior cruciate ligament reconstruction. $\mathrm{A}$ randomized controlled trial. Am J Sports Med 2013;41:788-94.

66 Heijne A, Werner S. Early versus late start of open kinetic chain quadriceps exercises after $A C L$ reconstruction with patellar tendon or hamstring grafts: a prospective randomized outcome study. Knee Surg Sports Traumatol Arthrosc 2007:15:402-14.

67 Mikkelsen C, Werner S, Eriksson E. Closed kinetic chain alone compared to combined open and closed kinetic chain exercises for quadriceps strengthening after anterior cruciate ligament reconstruction with respect to return to sports. Knee Surg Sports Traumatol Arthrosc 2000;8:337-42.

68 Morrissey MC, Drechsler WI, Morrissey D, et al. Effects of distally fixated versus nondistally fixated leg extensor resistance training on knee pain in the early period after anterior cruciate ligament reconstruction. Phys Ther 2002;82:35-43.

69 Perry MC, Morrissey MC, King JB, et al. Effects of closed versus open kinetic chain knee extensor resistance training on knee laxity and leg function in patients during the 8- to 14-week post-operative period after anterior cruciate ligament reconstruction. Knee Surg Sports Traumatol Arthrosc 2005;13:357-69.

70 Uçar M, Koca I, Eroglu M, et al. Evaluation of open and closed kinetic chain exercises in rehabilitation following anterior cruciate ligament reconstruction. J Phys Ther Sci 2014;26:1875-8.

71 Augustsson J. Documentation of strength training for research purposes after $\mathrm{ACL}$ reconstruction. Knee Surg Sports Traumatol Arthrosc 2014;21:1849-55.

72 Gokeler A, Bisschop M, Benjaminse A, et al. Quadriceps function following ACL reconstruction and rehabilitation: implications for optimization of current practices. Knee Surg Sports Traumatol 2014;22:1163-74.

73 Kruse LM, Gray B, Wright RW. Rehabilitation after anterior cruciate ligament reconstruction. A systematic review. J Bone Joint Surg Am 2012;94:1737-48.

74 Baltaci G, Harput G, Haksever B, et al. Comparison between Nintendo Wii Fit and conventional rehabilitation on functional performance outcomes after hamstring 
anterior cruciate ligament reconstruction: prospective, randomized, controlled, double-blind clinical trial. Knee Surg Sports Traumatol Arthrosc 2013;21:880-7.

75 Berschin G, Sommer B, Behrens A, et al. Whole body vibration exercise protocol versus a standard exercise protocol after $A C L$ reconstruction: a clinical randomized controlled trial with short term follow-up. J Sports Sci Med 2014;13:580-9.

76 Bieler T, Sobol NA, Andersen LL, et al. The effects of high-intensity versus low-intensity resistance training on leg extensor power and recovery of knee function after ACL-reconstruction. Biomed Res Int 2014;2014:278512.

77 Cappellino F, Paolucci T, Zangrando F, et al. Neurocognitive rehabilitation approach effectiveness after anterior cruciate ligament reconstruction with patellar tendon. A randomized controlled trial. Eur J Phys Rehabil Med 2012;48:17-30.

78 Cooper RL, Taylor NF, Feller JA. A randomised controlled trial of proprioceptive and balance training after surgical reconstruction of the anterior cruciate ligament. Res Sports Med 2005;13:217-30.

79 Fu CLA, Yung SHP, Law KYB, et al. The effect of whole-body vibration therapy on neuromuscular control after anterior cruciate ligament reconstruction: a randomized controlled trial. Am J Sports Med 2013;41:804-14.

80 Gerber JP, Marcus RL, Dibble LE, et al. Safety, feasibility, and efficacy of negative work exercise via eccentric muscle activity following anterior cruciate ligament reconstruction. J Orthop Sports Phys Ther 2007;37:10-18.

81 Gerber JP, Marcus RL, Dibble LE, et al. Effects of early progressive eccentric exercise on muscle structure after anterior cruciate ligament reconstruction. J Bone Joint Surg Am 2007;89:559-70.

82 Gerber JP, Marcus RL, Dibble LE, et al. Effects of early progressive eccentric exercise on muscle size and function after anterior cruciate ligament reconstruction: a 1-year follow-up study of a randomized clinical trial. Phys Ther 2009;89:51-9.

83 Isberg J, Faxén E, Brandsson S, et al. Early active extension after anterior cruciate ligament reconstruction does not result in increased laxity of the knee. Knee Surg Sports Traumatol Arthrosc 2006;14:1108-15.

84 Kinikli Gl, Yüksel I, Baltaci G, et al. The effect of progressive eccentric and concentric training on functional performance after autogenous hamstring anterior cruciate ligament reconstruction: a randomized controlled study. Acta Orthop Traumatol Turc 2014;48:283-9.

85 Liu-Ambrose T, Taunton JE, MacIntyre D, et al. The effects of proprioceptive or strength training on the neuromuscular function of the $A C L$ reconstructed knee: a randomized clinical trial. Scand J Med Sci Sports 2003;13:115-23.

86 Moezy A, Olyaei G, Hadian M, et al. A comparative study of whole body vibration training and conventional training on knee proprioception and postural stability after anterior cruciate ligament reconstruction. Br J Sports Med 2008;42:373-8.

87 Risberg MA, Holm I, Myklebust G, et al. Neuromuscular training versus strength training during first 6 months after anterior cruciate ligament reconstruction: a randomized clinical trial. Phys Ther 2007;87:737-50.

88 Risberg MA, Holm I. The long-term effect of 2 postoperative rehabilitation programs after anterior cruciate ligament reconstruction: a randomized controlled clinical trial with 2 years follow-up. Am J Sports Med 2009;37:1958-66.

89 Sekir U, Gur H, Akova B. Early versus late start of isokinetic hamstring-strengthening exercise after anterior cruciate ligament reconstruction with patellar tendon graft. Am J Sports Med 2010;38:492-500.

90 Shaw T, Williams MT, Chipchase LS. Do early quadriceps exercises affect the outcome of $\mathrm{ACL}$ reconstruction? A randomized controlled trial. Austr J Phys 2005;51:9-17.

91 Tyler TF, McHugh MP, Gleim GW, et al. The effect of immediate weightbearing after anterior cruciate ligament reconstruction. Clin Orthop Relat Res 1998:141-8.

92 Risberg MA, Mørk M, Jenssen HK, et al. Design and implementation of a neuromuscular training program following anterior cruciate ligament reconstruction. J Orthop Sports Phys Ther 2001;31:620-31.

93 Imoto AM, Peccin S, Melo Almeida GJ, et al. Effectiveness of electrical stimulation on rehabilitation after ligament and meniscal injuries: a systematic review. Sao Paulo Med J 2011;129:414-23.

94 Kim KM, Croy T, Hertel J, et al. Effects of neuromuscular electrical stimulation after anterior cruciate ligament reconstruction on quadriceps strength, function, and patient-oriented outcomes: a systematic review. J Orthop Sport Phys Ther 2010;40:383-91.

95 Wasielewski NJ, Parker TM, Kotsko KM. Evaluation of electromyographic biofeedback for the quadriceps femoris: a systematic review. J Athl Train 2011;46:543-54.

96 Christanell F, Hoser C, Huber R, et al. The influence of electromyographic biofeedback therapy on knee extension following anterior cruciate ligament reconstruction: a randomized controlled trial. Sports Med Arthrosc Rehabil Ther Technol 2012;4:41.

97 Ediz L, Ceylan MF, Turktas U, et al. A randomized controlled trial of electrostimulation effects on effusion, swelling and pain after anterior cruciate ligament reconstruction: a pilot study. Clin Rehabil 2012;26:413-22.

98 Feil S, Newell J, Minogue C, et al. The effectiveness of supplementing a standard rehabilitation program with superimposed neuromuscular electrical stimulation after anterior cruciate ligament reconstruction: a prospective, randomized, single-blind study. Am J Sports Med 2011;39:1238-47.
99 Fitzgerald GK, Piva SR, Irrgang JJ. A modified neuromuscular electrical stimulation protocol for quadriceps strength training following anterior cruciate ligament reconstruction. J Orthop Sports Phys Ther 2003;33:492-501.

100 Paternostro-Sluga T, Fialka C, Alacamliogliu Y, et al. Neuromuscular electrical stimulation after anterior cruciate ligament surgery. Clin Orthop Relat Res 1999:166-75.

101 Taradaj J, Halski T, Kucharzewski M, et al. The effect of neuromuscular electrical stimulation on quadriceps strength and knee function in professional soccer players: return to sport after ACL reconstruction. Biomed Res Int 2013;2013:802534.

102 Lepley LK, Wojtys EM, Palmieri-Smith RM. Combination of eccentric exercise and neuromuscular electrical stimulation to improve biomechanical limb symmetry after anterior cruciate ligament reconstruction. Clin Biomech 2015;30:738-47.

103 Martimbianco AL, Gomes da Silva BN, de Carvalho AP, et al. Effectiveness and safety of cryotherapy after arthroscopic anterior cruciate ligament reconstruction. A systematic review of the literature. Phys Ther Sport 2014;15:261-8.

104 Raynor MC, Pietrobon R, Guller U, et al. Cryotherapy after ACL reconstruction: a meta-analysis. J Knee Surg 2005;18:123-9.

105 Hubbard TJ, Denegar CR. Does cryotherapy improve outcomes with soft tissue injury? J Athl Train 2004;39:278-9.

106 Edwards DJ, Rimmer M, Keene GCR. The use of cold therapy in the postoperative management of patients undergoing arthroscopic anterior cruciate ligament reconstruction. Am J Sports Med 1996;24:193-5.

107 Glenn RE, Spindler KP, Warren TA, et al. Cryotherapy decreases intraarticular temperature after $\mathrm{ACL}$ reconstruction. Clin Orthop Relat Res 2004:268-72.

108 Czuppon S, Racette BA, Klein SE, et al. Variables associated with return to sport following anterior cruciate ligament reconstruction: a systematic review. $\mathrm{Br}$ I Sports Med 2014;48:356-64.

109 Harris JD, Abrams GD, Bach BR, et al. Return to sport after ACL reconstruction. Orthopedics 2014;37:e103-8.

110 Narducci E, Waltz A, Gorski K, et al. The clinical utility of functional performance tests within one-year post-ACL reconstruction: a systematic review. Int I Sports Phys Ther 2011:6:333-42.

111 Müller U, Krüger-Franke $M$, Schmidt $M$, et al. Predictive parameters for return to pre-injury level of sport 6 months following anterior cruciate ligament reconstruction surgery. Knee Surg Sports Traumatol Arthrosc 2015;23:3623-31.

112 Thomeé R, Neeter C, Gustavsson A, et al. Variability in leg muscle power and hop performance after anterior cruciate ligament reconstruction. Knee Surg Sports Traumatol Arthrosc 2012;20:1134-51.

113 Everhart JS, Best TM, Flanigan DC. Psychological predictors of anterior cruciate ligament reconstruction outcomes: a systematic review. Knee Surg Sports Traumatol Arthrosc 2015:23:752-62.

114 te Wierike SC, van der Sluis A, van den Akker-Scheek I, et al. Psychosocial factors influencing the recovery of athletes with anterior cruciate ligament injury: a systematic review. Scand J Med Sci Sports 2012;23:527-40.

115 Gobbi A, Francisco R. Factors affecting return to sports after anterior cruciate ligament reconstruction with patellar tendon and hamstring graft: a prospective clinical investigation. Knee Surg Sports Traumatol Arthrosc 2006;14:1021-8.

116 Laboute E, Savalli L, Puig P, et al. Analysis of return to competition and repeat rupture for 298 anterior cruciate ligament reconstructions with patellar or hamstring tendon autograft in sportspeople. Ann Phys Rehabil Med 2010;53:598-614

117 Thomeé $\mathrm{P}$, Währborg $\mathrm{P}$, Börjesson $\mathrm{M}$, et al. Determinants of self-efficacy in the rehabilitation of patients with anterior cruciate ligament injury. J Rehabil Med 2007;39:486-92.

118 Zaffagnini S, Grassi A, Marcheggiani Muccioli GM, et al. Return to sport after anterior cruciate ligament reconstruction in professional soccer players. Knee 2014:21:731-5.

119 Swärd P, Kostogiannis I, Roos H. Risk factors for a contralateral anterior cruciate ligament injury. Knee Surg Sports Traumatol Arthrosc 2010;18:277-91.

120 Wright RW, Magnussen RA, Dunn WR, et al. Ipsilateral graft and contralateral ACL rupture five years or more following $A C L$ reconstruction. A systematic review. J Bone Joint Surg Am 2011;93:1159-65.

121 de Jong SN, Caspel DR, van Haeff MJ, et al. Functional assessment and muscle strength before and after reconstruction of chronic anterior cruciate ligament lesions. Arthroscopy 2007;23:21-8.

122 Mueller MJ, Maluf KS. Tissue adaptation to physical stress: a proposed "physica stress theory" to guide physical therapist practice, education, and research. Phys Ther 2002:82:383-403.

123 Claes S, Verdonk P, Forsyth R, et al. The 'ligamentization' process in anterior cruciate ligament reconstruction: what happens to the human graft? A systematic review of the literature. Am J Sports Med 2011;39:2476-83.

124 Janssen RPA, Wijk J, van derFiedler $A$, et al. Remodelling of human hamstring autografts after anterior cruciate ligament reconstruction. Knee Surg Sports Traumatol Arthrosc 2011;19:1299-306.

125 Ntoulia A, Papadopoulou F, Ristanis S, et al. Revascularization process of the bone-patellar tendon-bone autograft evaluated by contrast-enhanced magnetic resonance imaging 6 and 12 months after anterior cruciate ligament reconstruction. Am J Sports Med 2011;39:1478-86. 
126 Scheffler SU, Unterhauser FN, Weiler A. Graft remodeling and ligamentization after anterior cruciate ligament reconstruction. Knee Surg Sports Traumatol Arthrosc 2008; 16:834-42.

127 Della Villa S, Boldrini L, Ricci M, et al. Clinical outcomes and return-to-sports participation of 50 soccer players after anterior cruciate ligament reconstruction through a sport-specific rehabilitation protocol. Sports Health 2012;4:17-24.

128 Grindem H, Snyder-Mackler L, Moksnes H, et al. Simple decision rules can reduce reinjury risk by $84 \%$ after $\mathrm{ACL}$ reconstruction: the Delaware-Oslo $\mathrm{ACL}$ cohort study. Br J Sports Med 2016;50:804-8.

129 Hildebrandt C, Müller L, Zisch B, et al. Functional assessments for decision-making regarding return to sports following $\mathrm{ACL}$ reconstruction. Part I: development of a new test battery. Knee Surg Sports Traumatol Arthrosc 2015;23:1273-81.

130 Benjaminse A, Otten E. ACL injury prevention, more effective with a different way of motor learning? Knee Surg Sports Traumatol Arthrosc 2011;19:622-7.

131 Herbst E, Hoser C, Hildebrandt C, et al. Functional assessments for decision-making regarding return to sports following ACL reconstruction. Part II: clinical application of a new test battery. Knee Surg Sports Traumatol Arthrosc 2015;23:1283-91.
132 Maxwell JP, Masters RSW, Eves F. From novice to no know-how: a longitudinal study of implicit motor learning. J Sports Sci 2000;18:111-20.

133 Thomeé R, Kaplan Y, Kvist J, et al. Muscle strength and hop performance criteria prior to return to sports after ACL reconstruction. Knee Surg Sports Traumatol Arthrosc 2011;19:1798-805.

134 Aerts I, Cumps E, Verhagen E, et al. Efficacy of a 3 month training program on the jump-landing technique in jump-landing sports. Design of a cluster randomized controlled trial. BMC Musculoskelet Disord 2010:11:281.

135 Bell DR, Smith MD, Pennuto AP, et al. Jump-landing mechanics after anterior cruciate ligament reconstruction: a landing-error scoring system study. I Athl Train 2014;49:435-41.

136 Bien DP, Dubuque TJ. Considerations for late stage acl rehabilitation and return to sport to limit re-injury risk and maximize athletic performance. Int I Sports Phys Ther 2015;10:256-71.

137 Padua DA, Boling MC, DiStefano LJ, et al. Reliability of the Landing Error Scoring System-real time, a clinical assessment tool of jump-landing biomechanics. J Sport Rehabil 2011;20:145-56.

138 Smith HC, Johnson RJ, Shultz SJ, et al. A prospective evaluation of the Landing Error Scoring System (LESS) as a screening tool for anterior cruciate ligament injury risk. Am J Sports Med 2012;40:521-6. 